\title{
A study of the influence of deviant minority on visual judgements within a small group
}

\author{
YAEKO KOSEK $I^{1}$
}

Faculty of Economics, Meikai University, Urayasu-city, Chiba 279

\begin{abstract}
The influence which a deviant minority might exert over other members of a group was examined in three experiments in which the group consisted of five female members, who were given the task of estimating the number of random dots. The subjects were 163 fernale undergraduates. Some members of the group were confederates, confidently and consistently giving estimates much higher than actual. In the first experiment, groups consisted of either four confederates and one naive subject, or one confederate and four naive subjects. The results demonstrated that even a single and extreme deviant could exert a great deal of influence over the majority. In the second experiment, a deviant credited with a high level of ability also had a great deal of influence over the majority, but such an impact may be considcred to be less overt and latent. In the third experiment, the order in which the confederate spoke was varied among groups. When the deviant spoke first, she had the most influence, but she also had some effect, although it did not appear immediately, when she spoke in the middle of the group, or last of all.
\end{abstract}

Key words: conformity, innovation, deviant minority, consistency in behavioral style, visual judgement, high ability minority, order of speaking, implicit effect.

Moscovici (1976, 1985) proposes that researchers in the field of social influences should deal with processes whereby minorities or deviant elements within a group exert an influence over the majority. He stresses that every member of a group, without regard to his or her particular ranking, may be the source as well as the object of influence, and that the very existence of such assertive minorities changes the group and hence promotes innovation. $\mathrm{He}$ also says that consideration of modalities of the change and innovation within the group, alongside those of normalization and conformity, will provide a new perspective to the field of group dynamics. Since the publication of Moscovici and Faucheux (1972), there have been a great deal of research on minorities (Doms \& Van Avermaet, 1980; Mugny, Papasta-

1 The author is greatly indebted to Ms. R. Kawaguchi in conducting Experiments 1 and 2 . She would like to thank Professor T. Oyama, then at Nihon University for his helpful advice in improving the manuscript, and Mr. M. G. Remington of $Q \mathbf{E}$ school for checking English manuscript. mou, \& Sherrard, 1982; Nemeth \& Markovski, 1972; Nemeth \& Wachtler, 1974), but as Moscovici (1985) indicates, they have been concentrated in Europe and Great Britain. Moreover, these data do not always decisively indicate the influence of minority. This study was planned as the starting point of systematic research into the social influence process of minority by the author.

\section{Experiment 1}

The aim of Experiment 1 was to confirm the fact that, when members of a group perform a task, a deviant minority is capable of influencing the others. The extent of any such influence was investigated by placing no, one, or four deviant confederates in five-person groups for perceptual judgement. It was expected that, while four confederates would have stronger effects on a single naive subject, even a single deviant minority would exert an appreciable amount of influence over the majority. 


\section{Method}

Subjects. There were 60 subjects, and four confederates. All were female students from Senshu University. In this and subsequent experiments some of them were known, but most of them were unknown to each other. Twenty subjects were assigned to each of the three confederate conditions, in which five-person groups contained either no(Group 0/5), one(Group 1/5), or four(Group 4/5) confederates.

Stimuli. The visual stimuli to be judged were provided by a series of $9 \mathrm{~cm} \times 10.5 \mathrm{~cm}$ cards, on which random dots were printed. The numbers of dots were 53 (S53), 101 (S101), and 199 (S199). There were 30 cards in all, consisting of ten of each type with the same number and different patterns of dots.

Procedure. The experiment was disguised to the subjects as an investigation of visual perception. They were brought into the laboratory, seated around a desk, and told, "As this experiment is intended to investigate momentary perception, we would like you to estimate the number of dots without any reflection, and to give your answer orally. There is no set order of speaking." As each card was presented by the experimenter, the group members gave their estimates one after another, and an assistant made a note of them. The confederate(s) in fact always spoke first or at a very early stage, disregarding precedence and in a confident fashion. The cards were exposed for only about five seconds each, within which it was impossible to count the dots. The 30 cards were presented in a random order, and then shown again in the same order. The values to be given by the accomplices had been set at between 60 and 100 for S53, between 150 and 200 for S101, and around 800 for S199.

After all the cards had been shown and estimations given, the subjects were told the true purpose of the experiment.

\section{Results}

Table 1 shows the mean, the mean percentage to the actual number of dots, coefficient of variation, and range of the estimates for each stimulus type. The values in each cell were derived from the estimates made to each stimulus type by 20 subjects, each responding 20 times.

In general, there was a slight tendency to underestimate the number of dots in Group 0/5. In both Groups 1/5 and 4/5 the general level of estimate increased, and in fact came near the confederates' value. Although the estimates in Group 4/5 were the most inflated, the subjects in Group 1/5 also gave estimates which were much higher than those of Group 0/5 (Table 1).

The estimates were changed into the percentage of the actual number of dots and subjected to a split-plot analysis of variance with three factors: confederate condition, stimulus type and trial. All of main effects and first-order interactions turned out to be significant (Table 2). There were wide divergences in responce both between groups and between individuals. Taken as a whole, Group 1/5 produced greater divergence between individuals than Groups $0 / 5$ or $4 / 5(G=.53$ for S53, $G=.77$ for S101, and $G=.72$ for S199; $d f=399, p<.01$ for all, by Cochran's test).

\section{Discussion}

As was predicted, it was in Group 4/5 that the influence of the confederates was most clearly in evidence. Even so, the the data of Group 1/5 obviouly indicate that a deviant minority, even if only a single person, can exert influence over the other group members.

Examination of the data for individual stimulus type provides a detailed picture of deviant influence. In Groups 1/5 and $4 / 5$, the subjects' responses were quite stable for S53 and S199. Since the discrepancy between the responses of the confederates and the naive subjects for $\mathrm{S} 53$ 
Table 1

Means, means of percentages to actual number, coefficients of variation and ranges of estimate on number of random dots in Experiment 1

\begin{tabular}{lcccc}
\hline Stimulus & & Group $0 / 5(\mathcal{N}=20)$ & Group $1 / 5(\mathcal{N}=20)$ & Group $4 / 5(\mathcal{N}=20)$ \\
\hline S53 & mean & 41.8 & 58.1 & 69.0 \\
& $\%$ & $78.8 \mathrm{a}$ & $109.6 \mathrm{~b}$ & $130.2 \mathrm{~b}, \mathrm{c}$ \\
& & $(26.7)$ & $(38.5)$ & $(24.4)$ \\
& range & $29.8-51.5$ & $32.3-81.0$ & $48.2-86.2$ \\
S101 & mean & 75.8 & 148.4 & 171.6 \\
& $\%$ & $74.9 \mathrm{a}$ & $146.9 \mathrm{c}, \mathrm{d}$ & $169.9 \mathrm{~d}, \mathrm{e}$ \\
& & $(24.5)$ & $(67.1)$ & $(27.4)$ \\
& range & $49.5-93.3$ & $65.3-235.0$ & $106.5-259.5$ \\
& mean & 141.7 & 377.0 & 707.0 \\
& $\%$ & $71.0 \mathrm{a}$ & $189.4 \mathrm{e}$ & $355.3 \mathrm{f}$ \\
& & $(24.0)$ & $(61.0)$ & $(29.6)$ \\
& range & $96.5-190.5$ & $121.0-725.0$ & $195.5-864.0$
\end{tabular}

Note: Ranges are based upon the mean of each individual's estimates on 20 trials.

Values with different subscripts are significantly different $(p<.01)$ by Duncan's new multiple range test.

Values in parentheses are coefficients of variation.

Table 2

Analysis of variance in Experiment 1

\begin{tabular}{|c|c|c|c|c|}
\hline$S V$ & $S S$ & $d f$ & $M S$ & $F$ \\
\hline Between subjects & 18575800 & 59 & & \\
\hline Confederates (A) & 12374000 & 2 & 6186990.0 & $56.86^{* *}$ \\
\hline Subj w. groups & 6201770 & 57 & 108803.0 & \\
\hline Within subjects & 22706500 & 3540 & & \\
\hline Stimulus & 6391920 & 2 & 3195960.0 & $123.42 * *$ \\
\hline $\mathrm{A} \times \mathrm{B}$ & 6445740 & 4 & 1611440.0 & $62.23^{* *}$ \\
\hline $\mathrm{B} \times$ subj w. groups & 2951980 & 114 & 25894.6 & \\
\hline Trial $\quad(\mathrm{C})$ & 395256 & 19 & 20802.9 & $9.89 * *$ \\
\hline $\mathrm{A} \times \mathrm{C}$ & 170784 & 38 & 4494.3 & $2.14^{* *}$ \\
\hline $\mathrm{C} \times \operatorname{subj}$ w. groups & 2276890 & 1083 & 2102.4 & \\
\hline $\mathrm{B} \times \mathrm{C}$ & 308240 & 38 & 8111.6 & $5.05 * *$ \\
\hline $\mathrm{A} \times \mathrm{B} \times \mathrm{C}$ & 284936 & 76 & 3749.2 & $2.33^{* *}$ \\
\hline $\mathbf{B} \times \mathbf{G} \times$ subj w. groups & 3480780 & 2166 & 1607.0 & \\
\hline Total & 41282300 & 3599 & & \\
\hline
\end{tabular}

was comparatively small, it was easy for the latter to follow the consistent confederates (Allen, 1965, 1975; Koseki, 1983). With S199, which was extremely difficult to judge, the subjects had no standard for judging whether the confederates' responses were or were not deviant, even if in fact they were extremely deviant. 
Thus it may be reasonable to think that the subjects again took the confederates' confident responses as a standard for their own judgement. On the other hand, during the trials with S101, judgements of Group 1/5 fluctuated and were unstable. In several preparatory experiments conducted by the author, judgements of the stimulus type like S101 under the similar situations had always been found to be unsteady. This suggests that here the process of influence did not take place in any straightforward way, and that the subjects may have experienced considerable uncertainly and strain. They probably on the one hand recognized the discrepancy between their own judgements and those of the confederate, but on the other placed trust and became dependent on her, because she acted consistently and confidently.

\section{Experiment 2}

Moscovici (1985) differentiates "the variables, which determine the influence phenomenon, from the parameters, which merely hamper or facilitate it: the former concerning with specific aspects of phenomena, and the latter affecting their respective weight in a given population" (p. 367).

In this experiment, the ability of the deviant minority, which is considered as one of parameters, was manipulated. Naturally, it was presumed that the high ability deviant would exert more influence over the other group members than one with low ability.

\section{Method}

Subjects. Forty feamle students from Tokyo Kasei College were the subjects of this experiment, with two students from the same college acting as confederates, of whom one served as the high ability individual and the other as the low ability one throughout the experiment. Twenty subjects in all were assigned to each of the two experimental conditions.

Procedure. The experiment consisted of three sessions. The tasks were performed in groups of five, of whom one was a confederate. The five individuals came into the laboratory and sat with the experimenter around a large desk. They were led to believe that they would be taking part in two experiments.

[Fist session] This session was set up in order to manipulate the apparent ability of the confederate. The members were each given the task of solving 160 anagrams, of which there were twenty to a page in a booklet. They were given a minute for each page. When the minute was up they stopped working, whether they had completed the task or not, and orally reported to the experimenter what they had achieved, before going on to the next page. In this way, every member of the group could know each other's performance.

In Low-Ability Group (Lo-A. G.) the accomplice solved only two or three anagrams per page, whereas the confederate in High-Ability Group (Hi-A.G.), who had memorized the answers, gave a complete set of correct solutions.

[Second session] When the first session was over, the subjects were asked to take part in a further experiment on perception, following which they performed the task of estimating the number of dots of the same stimulus types by the same procedure as in Experiment 1 with the same group members in the previous session. The confederate always gave the same values as in Experiment 1 in a confident and consistent manner early on each trial.

[Third seesion] Each member of the group rated, on a seven point scale, the degree of difficulty of the estimation task and, using the SD method, of her impressions of the other four group members. At the end of the session the subjects were informed of the true purpose of the experiment. 


\section{Results}

The evaluations on impressions made by the group members of their fellow members show that the confederate in Hi-A.G. was considered stronger $(F(2,176)=9.34$, $p<.01)$, more highly capable $(F(2,176)=$ $6.65, p<.01)$, and more assertive $(F(2,176)$ $=6.74, p<.01)$ than the others or the confederate of low ability. As to the evaluation of consistency there was no significant difference between conditions.

Table 3 shows the mean, percentage to the actual number of dots, coefficient of variation, and range of the estimates given. All the estimated values were changed into the percentages and subjected to a splitplot analysis of variance with three factors: ability, stimulus type, and trial. All three main effects and all first order interactions were statistically significant (Table 4). Duncan's new multiple range test indicated that there was no significant difference in the mean value between Hi-A.G. and Lo-A.G. for S53 or S101. Only with S199 was H-A.G. considerably larger than in Lo-A.G. (Table 3).

\section{Discussion}

Subjects' impressions of fellow members indicate that the manipulation of the confederates' apparent level of ability was successful.

The results suggest that the influence of the minority occurred in a different way than in Experiment 1. It was expected that the high ability minority would exert an appreciable influence, but in fact she had no recognizable impact in $\mathrm{S} 53$ or S101 (Table 3). However, in S199, which was apparently the most ambiguous and difficult to judge, the estimates given in Hi-A.G. and Lo-A.G. were both higher than those made by Group $0 / 5$ in Experiment $1^{2}$ (Group 0/5 vs. Lo-A.G.: $d f=798$,

2 This comparison may be inappropriate since the subjects in Experiment 2 came from a different college from those in Experiment 1. $t=16.6, p<.001$; Group 0/5 vs. Hi-A.G.: $d f=798, t=17.1, p<.001)$. Further, the discrepancy of the estimate values between the two conditions became evident only for S199 (Table 3). These results show that the consistent individual could exert her influence whether her ability was low or high, and at the same time give support to Moscovici's assumption that the factor of ability is one of the parameters which affect the amount of influence (1985). The results also support his assertion (Moscovici, 1980) that since the conflicts aroused by a minority are personal in nature and internalized by the subject, their influence would be implicit and not easy to reveal itself. It seems likely that the members of the high ability group were quite considerably disturbed by the deviant responses given by a group member they took to be more able than themselves. Even so, they were unable openly to follow her example in front of the others; but the influence of the minority came to the surface when the stimulus was extremely ambiguous. In this way, the experimental subjects managed to avoid, for a time, following blindly the example given by the more gifted individual.

Once again considerable variations of response between individuals and groups were observed. Nevertheless, the influence exerted by the high ability minority was a remarkable one. Figure 1 shows the pattern of response of the single subject in each group who gave the highest and lowest overall estimates for S199 over the course of the 20 judgements made. The dotted line in Fig. 1 shows the pattern of reactions to $\mathrm{S} 199$ of the individual who gave the highest overall estimates in Group 1/5 of Experiment 1. The differences in the maximum estimates between two ability conditions were striking; the high ability deviant was able to exert a decisive influence over a particular individual. It is supposed that subjects who gave answers even higher than the high ability minority did so out of determina- 


\section{Table 3}

Means, means of percentages to the actual number, coefficients of variation and ranges of estimates on number of random dots in Experiment 2

\begin{tabular}{cccc}
\hline Stimulus & & $\begin{array}{c}\text { Lo-A.G. } \\
(\mathcal{N}=20)\end{array}$ & $\begin{array}{c}\text { Hi-A.G. } \\
(\mathcal{N}=20)\end{array}$ \\
\hline S53 & mean & 50.7 & 49.3 \\
& $\%$ & $95.7 \mathrm{a}$ & $93.0 \mathrm{a}$ \\
& range & $(33.4)$ & $(28.8)$ \\
& mean & $33.0-74.9$ & $30-0-62.5$ \\
& $\%$ & 98.1 & 103.4 \\
& range & $97,1 \mathrm{a}$ & $102.3 \mathrm{a}$ \\
& mean & $(34.8)$ & $(65.2)$ \\
& $\%$ & $55.3-157.0$ & $79.1-146.5$ \\
& & 213.6 & 381.3 \\
& range & $107.4 \mathrm{a}$ & $191.6 \mathrm{~b}$ \\
& & $(37.3)$ & $(72.7)$ \\
& & $144.0-346.5$ & $154.0-944.0$
\end{tabular}

Note: Ranges are based upon the mean of individual's estimates on 20 trials.

There are significant differences $(p<.01)$ between values with subscript $a$ and $b$ by Duncan's new multiple range test.

Values in parentheses are coefficients of variation.

Table 4

Analysis of variance in Experiment 2

\begin{tabular}{|c|c|c|c|c|}
\hline$S V$ & $S S$ & $d f$ & $M S$ & $F$ \\
\hline Between subjects & 2889030 & 39 & & \\
\hline Ability $\quad$ (A) & 502746 & 1 & 502746.0 & $8.01^{* *}$ \\
\hline Subj w. groups & 2386290 & 38 & 62797.1 & \\
\hline Within subjects & 11353400 & 2360 & & \\
\hline Stimulus $\quad$ (B) & 1478820 & 2 & 739410.0 & $17.13^{* *}$ \\
\hline$A \times B$ & 924872 & 2 & 462436.0 & $10.71 * *$ \\
\hline $\mathrm{B} \times \operatorname{subj} \mathrm{w}$. groups & 3280720 & 76 & 43167.4 & \\
\hline Trial & 288232 & 19 & 15170.1 & $5.82 * *$ \\
\hline $\mathrm{A} \times \mathrm{C}$ & 116416 & 19 & 6127.2 & $2.35^{* *}$ \\
\hline $\mathbf{C} \times \operatorname{subj}$ w. groups & 1880360 & 722 & 2604.4 & \\
\hline $\mathrm{B} \times \mathrm{C}$ & 275414 & 38 & 7247.7 & $3.49 * *$ \\
\hline $\mathbf{A} \times \mathbf{B} \times \mathbf{C}$ & 113854 & 38 & 2996.2 & 1.44 \\
\hline $\mathbf{B} \times \mathbf{C} \times \operatorname{subj}$ w. groups & 2994760 & 1444 & 2073.9 & \\
\hline Total & 14242500 & 2399 & & \\
\hline
\end{tabular}

tion to emphasize their own independence and autonomy. This suggests that, in the responses it produces and in the underlying causes of its effects, the influence exerted by a minority may differ from the normalizing inlluence exerted by a majority 
(Moscovici, 1976, 1985).

\section{Experiment 3}

In the two previous experiments it was demonstrated that the deviant minority could produce conformity in the majority in favour of the minority viewpoint. However, there remain several problems in need of solution. Moscovici proposes that the most important factor involved in deviant minority influence is consistency of behavioral style. However, it is unclear whether the influence excercised by the deviant minority in the previous experiments was caused by the "behavioral consistency" (Moscovici \& Faucheux, 1972), or simply by the fact that, by speaking first, she provided a standard of judgement on which the others could base their responses. In the former, the deviant minority could have been able to exert a fair degree of influence over the others wherever in the group she spoke; but in the latter case, hardly any influence would be apparent if she spoke out later than others. Thus in the present experiment, the order in which the deviant confederate spoke was varied among groups.

It was predicted that the deviant minority would have the greatest influence over the others when she spoke out first. If we further take into consideration such factors as sequency, primacy, and recency, it would seem that the first speaker will have the greatest effect, followed by the last speaker, with an individual who speaks in the middle of the group having the least effect.

In addition, the disruption caused by a minority is expected to be covert and internalized, and its impact will reveal itself slowly (Moscovici, 1980; Moscovici \& Lage, 1976). In the present experiment, provision was made for an extra session, in which the participants made individual judgements, in order to investigate the persistense of any such effects.

\section{Method}

Subjects. Sixty-three female students at Tokyo Kasei College in the freshman through senior years acted as subjects. Fifteen were assigned to the control condi-

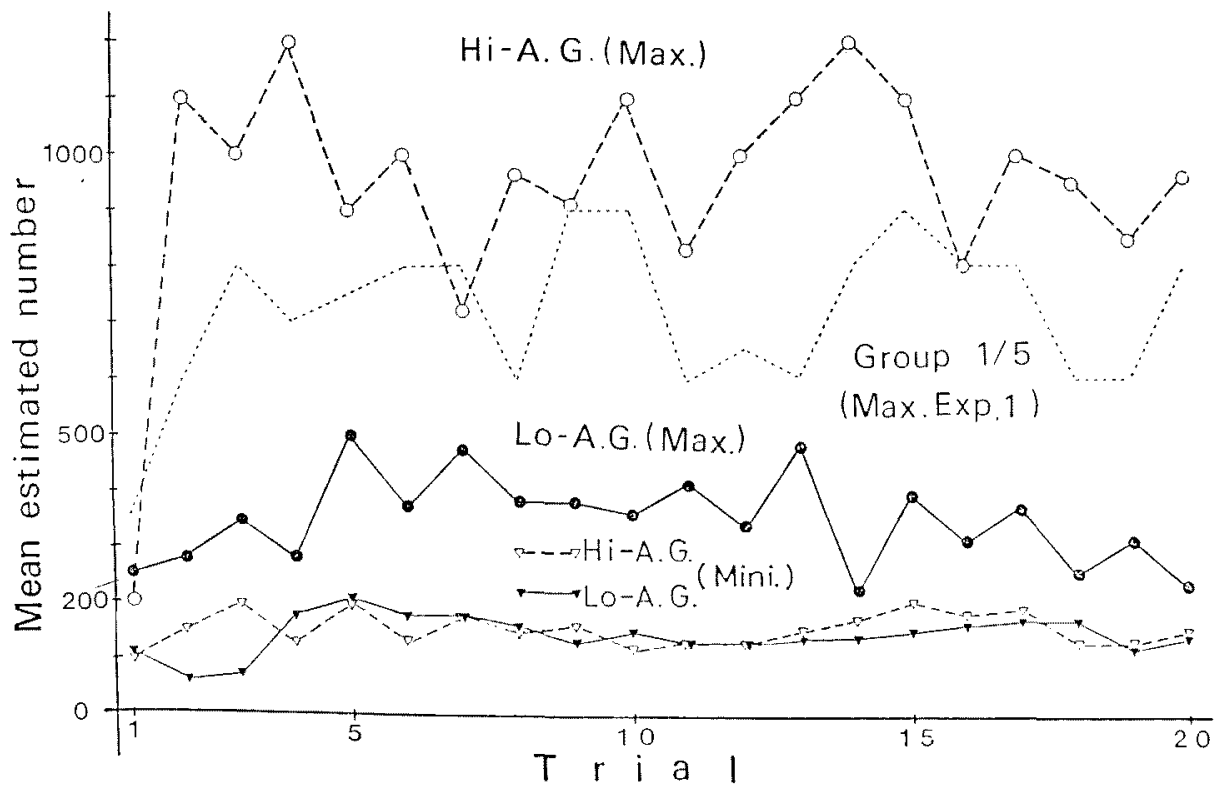

Fig. 1. Maximum and minimum estimates on number of 199 random dots in Experiment 2. 
tion; the other 48 were assigned to three experimental conditions, each consisting of four groups of five people. In addition, one female student from the same college served as an accomplice in all experimental groups.

Stimuli. Eight slides showing random arrangements of dots were used. The number of dots was: $48\left(\mathrm{~S}_{1}\right), 95\left(\mathrm{~S}_{2}\right)$, $143\left(\mathrm{~S}_{3}\right), 184\left(\mathrm{~S}_{4}\right), 220\left(\mathrm{~S}_{5}\right), 260\left(\mathrm{~S}_{6}\right), 297\left(\mathrm{~S}_{7}\right)$ and $335\left(\mathbf{S}_{8}\right)$.

Procedure. The experiment was ostensibly carried out as an investigation of visual perception. The task of giving estimates of the number of dots was performed in groups. Each member sat in front of the card with a number, from one to five, which, they were told, corresponded to the order of speaking.

[Experimental conditions] There were three experimental conditions, in which the deviant minority, in each of two oral sessions, gave the estimate either first (TopConfederate Group: Top-G.G.), third (Middle-C.G.), or last (Last-G.G.) in the consistent and confident fashion. In the control condition (No-C.G.), each group consisted of five true subjects.

[Confederate's responses] The responses given by the confederate in the oral sessions were at least double the true values. They were; either 90 or 100 for $S_{1}$ (48 dots), 230 or 250 for $\mathrm{S}_{2}$ (95 dots), 320 or 350 for $\mathrm{S}_{3}(143$ dots $), 400$ or 420 for $\mathrm{S}_{4}(184$ dots $)$, 550 or 560 for $S_{5}(220$ dots), 650 or 700 for $\mathrm{S}_{6}(260$ dots $), 720$ or 800 for $\mathrm{S}_{7}(297$ dots $)$, and 860 or 900 for $S_{8}(335$ dots). These values had been previously written down faintly only on the answering sheet delivered to the confederate.

[First session (group judgements: given orally)] The experimenter distributed answer sheets on which all members were to record their estimates. They were told to make an immediate estimate of the number of random dots displayed on the screen, and to announce it orally, in the order designated. Each slide was shown for about three seconds, a time within which it was impossible to count the number of dots. When the first stimulus was removed, and everyone had given her estimate and noted it down on the sheet provided, the next stimulus was shown. The same procedure was repeated eight times for the eight stimuli, shown in a random order.

[Second session (group judgements: given orally)] The subjects were told that the experiment would now be repeated with the same stimuli and the same order as before. The experimenter reloaded the slide magazine in front of the group members, and distributed a new answer sheet.

This session was set up to allow the group a second opportunity to observe the confederate responses; since, in the first session, those members of Middle-G.G. and Last-C.G. who gave their answers before the confederate spoke out, had not been in the position to know the latter's response to the stimulus being displayed.

[Third session (individual judgements: given in writing)] The subjects were told that a sequence of eight different slides would be shown, and they were asked once again to estimate the number of dots, but this time merely making a note on the answer sheets. The experimenter put a separately prepared magazine of eight slides into the projector. In fact these stimuli were exactly the same as those used in the previous sessions: only the order was different. The subjects working in silence recorded their own estimates as each stimulus was displayed.

Upon completion of each session, the answer sheets were taken in by the experimenter. After the third session, all those taking part filled in a questionnaire to rate the task difficulty and the extent of others' influence on their judgements, using a fivepoint Likert Scale; if they had been influenced by anyone else, they were to state which other member of the group had exercised the most influence over them.

Finally, they were informed of the true 
Table 5

Means of percentages of estimate given to the actual number of dots and coefficients of variation in Experiment 3

\begin{tabular}{cccccc}
\hline \multirow{2}{*}{ Session } & $\begin{array}{c}\text { No-G.G. } \\
(\mathcal{N}=15)\end{array}$ & $\begin{array}{c}\text { Top-G.G. } \\
(\mathcal{N}=16)\end{array}$ & $\begin{array}{c}\text { Middle-G.G. } \\
(\mathcal{N}=16)\end{array}$ & $\begin{array}{c}\text { Last-C.G. } \\
(\mathcal{N}=16)\end{array}$ & $\begin{array}{c}\text { All } \\
(\mathcal{N}=63)\end{array}$ \\
\hline \multirow{2}{*}{ 1st } & $74.1 \mathrm{a}$ & $168.0 \mathrm{e}$ & $85.0 \mathrm{a}$ & $76.2 \mathrm{a}$ & 101.3 \\
& $(59.3)$ & $(47.2)$ & $(54.9)$ & $(54.9)$ & $(66.9)$ \\
2nd & $72.5 \mathrm{a}$ & $192.7 \mathrm{f}$ & $105.1 \mathrm{~b}, \mathrm{c}$ & $94.1 \mathrm{~b}$ & 116.8 \\
& $(49.2)$ & $(48.2)$ & $(53.3)$ & $(40.8)$ & $(65.0)$ \\
3rd & $79.8 \mathrm{a}$ & $218.4 \mathrm{~g}$ & $122.4 \mathrm{~d}$ & $107.5 \mathrm{~b}, \mathrm{c}$ & 132.9 \\
& $(49.4)$ & $(49.3)$ & $(65.9)$ & $(41.0)$ & $(68.1)$ \\
\hline \multirow{2}{*}{ All } & 75.5 & 193.1 & 104.2 & 92.6 & 117.0 \\
& $(52.9)$ & $(49.9)$ & $(62.0)$ & $(46.9)$ & $(68.1)$
\end{tabular}

Note: Significant levels by Duncan's new multiple range test.

n.s.: between the values with same subscripts.

$p<.05$ : between the values with $c$ and $d$.

$p<.01$ : between the values with different subscripts, except between $c$ and $d$.

Values in parentheses are coefficients of variation.

purpose of the experiment, and given a small reward.

\section{Results}

All the estimate data were changed into the percentage of the actual number of dots (Table 5).

First of all, considering that in MiddleG.G. there might be differences between estimates given before and after the confederate spoke out, the data in this condition were subjected to a split-plot analysis of variance with three factors: position (before and after the confederate), session, and stimulus. Although main effects of session and stimulus factors were statistically significant (session: $F(2,28)=9.98, p<.01$; stimulus: $F(7,98)=6.37, p<.01)$, there was no significant difference in the position factor $(F(1,368)=.23)$. Hence, it can be considered that there was no effect of the speaking position.

Table 6 shows the results of a split-plot analysis of variance with three factors (position, session and stimulus) for the data in all conditions. Every main effect and first-order interaction was statistically significant. Overall, the mean percentages tended to increase in the three experimental groups as the sessions progressed. As expected, in Top-C.G. subjects gave the highest estimates. However, contrary to expectation, the smallest increase in estimates occurred in Last-C.G.. In TopG.G., higher estimates were already apparant in the first session, whereas Middle-C.G. and Last-G.C. were not significantly different from No-C.G.. In the second and third sessions, the estimates given by all three exprimental groups were higher than those of the control group (Table 5).

Table 7 gives the results of questionnaire. In every experimental condition, subjects judged the task imposed to have been of medium difficulty: In this there was no difference between the conditions $(F(3$, $59)=1.15$ ). Most of the subjects felt that they had been most heavily influenced by the first speaker followed by the entire group. No one mentioned the fourth or fifth speaker as having had any influence.

\section{Discussion}

Results show, as those of Experiments 1 and 2 , that a single deviant individual can exert a great deal of influence over the majority and also that the first speaker has considerable power to influence the others. It is reasonable to assume that because 
Table 6

Analysis of variance in Experiment 3

\begin{tabular}{|c|c|c|c|c|}
\hline$S V$ & $S S$ & $d f$ & $M S$ & $F$ \\
\hline Between subjects & 5641450 & 62 & & \\
\hline Position & 3134890 & 3 & 1044960.0 & $24.60^{* *}$ \\
\hline Subj w. groups & 2506560 & 59 & 42484.1 & \\
\hline Within subjects & 3959240 & 1449 & & \\
\hline Session & 251720 & 2 & 125860.0 & $34.76^{* *}$ \\
\hline$A \times B$ & 67322 & 6 & 11220.3 & $3.10^{* *}$ \\
\hline $\mathbf{B} \times$ subj w. groups & 427238 & 118 & 3620.7 & \\
\hline Stimulus $\quad(\mathrm{C})$ & 295654 & 7 & 42236.3 & $15.43^{* *}$ \\
\hline $\mathrm{A} \times \mathrm{C}$ & 348572 & 21 & 16598.7 & $6.06^{* *}$ \\
\hline $\mathrm{G} \times$ subj w. groups & 1130770 & 413 & 2737.9 & \\
\hline $\mathrm{B} \times \mathrm{C}$ & 97094 & 14 & 6935.3 & $4.51^{* *}$ \\
\hline $\mathbf{A} \times \mathbf{B} \times \mathbf{C}$ & 71030 & 42 & 1691.2 & 1.10 \\
\hline $\mathrm{B} \times \mathrm{C} \times \operatorname{subj}$ w. groups & 1269840 & 826 & 1537.3 & \\
\hline Total & 9600690 & 1511 & & \\
\hline
\end{tabular}

Table 7

Means of evaluation in questionnaire in Experiment 3

\begin{tabular}{cccccc}
\hline & No-C.G. & Top-C.G. & Middle-C.G. & Last-C.G. & Total \\
\hline $\begin{array}{l}\text { How difficult was the task? } \\
\text { (1: least-5: most) }\end{array}$ & 2.93 & 3.13 & 2.69 & 3.06 & 2.95 \\
$\begin{array}{l}\text { How influenced from others? } \\
\text { (1: not at all-5: much) }\end{array}$ & 3.13 & 3.06 & 2.56 & 2.56 & 2.82 \\
\hline
\end{tabular}

The most influencial person as named by subjects

$\begin{array}{rrrrrrr}\text { Speaker } & \text { No. } 1 & 4 & 9 & 4 & 5 & 22 \\ \text { No. } 2 & 1 & 1 & 1 & 1 & 4 \\ \text { No. } 3 & 0 & 0 & 0 & 2 & 2 \\ \text { No. } 4 & 0 & 0 & 0 & 0 & 0 \\ \text { No. } 5 & 0 & 0 & 0 & 0 & 0 \\ \text { all } & 4 & 3 & 6 & 3 & 16\end{array}$

most of the visual stimuli used were extremely ambiguous, the subjects were in search of information that could provide a basis or clue for their own judgements. It follows that under conditions such as those in this experiment, "informational influence" can readily become a decisive factor (Deutsch \& Gerard, 1955).

One fact deserving attention is that in Middle-C.G. and Last-G.G. the influence of the deviant minority was not particular- ly in evidence in the group judgement, but in the third session when the group members were left free to make their own individual judgements, there were clear indications of the influence of the deviant minority. These results support the proposition made by Moscovici (1980) that the disruption provoked by a minority would be internalized, and that its personal nature would result in its effects becoming apparent later. 
Even so, these effects do not provide sufficient explanation for the minority's ability to influence others, or of the processes involved in such influence. Conformity by the majority towards the minority may be, as in the situation described by Sherif (1936), merely one aspect of a simple normalization process; a whole range of responses converged upon a single one. But this view cannot account for the fact that the first speaker had such extreme power to influence the others, nor that in the third session, where the subjects worked individually, the responses given by the other group members in all experimental conditions were drawn near to those of the minority; nor was this influence clearly apparent in Middle-C.G. and Last-G.G..

As regards the influence of the first speaker, the very act of speaking out first may imply some type of consistent and autonomous behavior although allowance should be made for the fact that in the present experiment the order of speaking had been previously determined by the experimenter, this possibly putting a restriction on such influence. A possibility remains that a "snowball" effect took place, in which the first speaker influenced the second, these two the third, and so on. It may be that if a second consistent minority takes a moderate line in opposition to the deviant minority, the latter's influence may be dissipated (Koseki, 1986).

\section{Conclusion}

Firstly, it was demonstrated in three experiments that in a small group a consistent minority could exert a great influence over the others, despite the deviate nature of her behavior or, alternatively, because that deviant stance marked her out as independent and autonomous. Secondly, though the members of the group seemed to avoid explicitly following a minority who had a high degree of ability, the latter's influence became apparant as the ambiguity of their task increased (Experi- ment 2). Thirdly, the deviant minority had the power to influence the others wherever in the group she spoke, but the earlier she spoke, the more influence she exerted (Experiment 3). Fourthly, The results of Experiment 2 and those of the third session in Experiment 3 suggest that the mechanism or social process of minority influence is different from that of majority pressure: they support Moscovici's contention (1980, 1985) that minority influence tend to be implicit and private and that its effects would show some persistence.

It remains necessary to examine minority influence in a situation where a group is given a more complex task, such as the assessment of attitudes or opinions. Further, the procedure whereby the deviant minority speaks out before the others, which has been adopted in most previous experiments, requires more detailed analysis. In an immediate need of an examination is how the influence of the first deviant speaker might be blocked by opposition from a second consistent $\mathrm{mi}$ nority.

\section{References}

Allen, V. L. 1965 Situational factors in conformity. In L. Berkowitz (Ed.), Advances in experimental social psychology. Vol. 2. New York: Academic Press. Pp. 133-175.

Allen, V. L. 1975 Social support for nonconformity. In L. Berkowitz (Ed.), Advances in experimental social psychology. Vol, 8. New York: Academic Press. Pp. 1-43.

Deutsch. M., \& Gerard, H. B. 1955 A study of normative and informational social influence upon individual judgment. Journal of Abnormal and Social Psychology, 51, 629-636.

Doms, M., \& Van Avermaet, E. 1980 Majority influence, minority influence and conversion behavior: a replication. Journal of Experimental Social Psychology, 16, 283-292.

Koseki, Y. 1983 A study on factors inducing boomerang effects in persuasive communication: concerning opinion discrepancy and forced commitment. Japanese Journal of Psychology, 54, 1-8. (In Japanese with English abstract) 
Koseki, Y. 1986 Manual of experimental psychology. Department of Educational Psycology, University of Gunma. (In Japanese unpublished)

Moscovici, S. 1976 Social infuence and social change. London: Academic Press.

Moscovici, S. 1980 Toward a theory of conversion behavior. In L. Berkowitz (Ed.), Advances in experimental social psychology. Vol. 13. New York: Academic Press. Pp. 209-239.

Moscovici, S. 1985 Social influence and conformity. In G. Lindzey \& E. Aronson (Eds.), Handbook of social psychology. 3rd ed. Vol. 2. New York: Random House. Pp. 347-412.

Moscovici, S., \& Faucheux, C. 1972 Social influence, conformity bias, and the study of active minorities. In L. Berkowitz (Ed.), Advances in experimental social psychology. Vol. 6. New York:
Academic Press. Pp. 149-202.

Moscovici, S., \& Lage, E. 1976 Studies in social influence. III: Majority versus minority influence in a group. European Journal of Social Psychology, 6, 149-174.

Mugny, G., Papastamou, S., \& Sherrard, C. 1982 The power of minorities. London: Academic Press.

Nemeth, C., \& Markovski, J. 1972 Conformity and discrepancy of position. Sociometry, 35, 562575.

Nemeth, C., \& Wachtler, J. 1974 Creating the perceptions of consistency and confidence: a necessary condition for minority influence. Sociometry, 37, 529-540.

Sherif, M. 1936 The psychology of social norm. New York: Harper \& Row.

(Received Jan. 22, 1987; accepted May 13, 1989) 